\title{
Research and Policy to Achieve Healthy Aging in Asia: Recommendations from an Expert Workshop
}

\author{
Ng Tze Pin ${ }^{1}$, Balasubramanyam Muthuswamy ${ }^{2},{\text { Fenech } \text { Michael }^{3} \text {, Head Richard }}^{4}$ Amarra Maria \\ Sofia $^{*}, 5$ and Loke Seng Cheong ${ }^{6}$
}

\author{
${ }^{1}$ Department of Psychological Medicine, NUHS Tower Block, Level 9, National University Hospital, Singapore, 15 \\ Lower Kent Ridge Road, Singapore 119074 \\ ${ }^{2}$ Madras Diabetes Research Foundation, No.4, Conran Smith Road, Gopalapuram, Chennai 600 086, India \\ ${ }^{3}$ CSIRO Animal, Food and Health Sciences - Adelaide, Kintore Ave., Adelaide SA 5000, Australia \\ ${ }^{4}$ Research and Innovation Chancellery, University of South Australia, Level 4 Hawke Building, 55 North Terrace, City \\ West Campus, GPO Box 2471 Adelaide SA 5001, Australia \\ ${ }^{5}$ International Life Sciences Institute Southeast Asia Region, 9 Mohamed Sultan Road \#02-01, Singapore 238959 \\ ${ }^{6}$ Institute of Gerontology, Universiti Putra Malaysia, UPM Serdang, 43400 Serdang, Malaysia
}

\begin{abstract}
Asia has currently one of the largest concentrations of aging persons in the world. This trend is expected to continue due to increasing longevity and continued fertility reductions in its member countries. Asian countries need to start planning for these future demographic changes by formulating evidence-based policies to address aging. A workshop on healthy aging in Asia was recently organized by the International Life Sciences Institute Southeast Asia (ILSI SEA) Region in Singapore ${ }^{1}$. The goal was to discuss aging-related issues in the region and identify ways to address these issues through scientific research. Policy issues that were identified include: difficulty in translating scientific findings into policy initiatives, lack of government financial resources to support agingresearch, food insecurity among Asian elderly, and diverse ethnic populations that necessitate tailored interventions to address specific health problems. Better quality of health rather than increased longevity was seen as an important goal to strive for. Health issues identified include: maintaining autonomy and independence in a developing country context, developing fitness standards for Asians, examining how Asian populations transition into disability, and identifying health pathways in developing countries, among others. Multi-disciplinary and collaborative research is the best approach to address these issues. Future actions include the establishment of a regional consortium or collaborative network to guide the research agenda that can support aging policies as well as the exploitation of existing opportunities for public-private partnerships.
\end{abstract}

Keywords: Aging, Asia, Asian elderly, healthy aging, policy, research.

\section{INTRODUCTION}

\section{The Aging Situation in Asia}

The Asia-Pacific region is currently inhabited by over 4.2 billion people, constituting 60percent of the world's population [1]. One of the fastest growing segments is the population of individuals aged 60 years and over.According to the UN Economic and Social Commission for Asia and the Pacific [2], one in four people in the region will be 60 years or

*Address correspondence to this author at the International Life Sciences Institute Southeast Asia Region, 9 Mohamed Sultan Road \#02-01, Singapore 238959; Tel. +65 6352 5220; Fax: +65 6352 5536;

E-mails: sofiaamarra@ilsisea.org.sg; amarra.sofia@gmail.com

${ }^{1}$ Workshop held after the conference on Healthy Aging in Asia: Strategies to Meet Health and Lifestyle Challenges, Grand Copthorne Waterfront Hotel, Singapore, 4-6 March, 2013 older by the year 2050, rising from one in 10 in 2010. Due its large population size, Asia has one of the largest concentrations of globally aging persons [2].

Fig. (1) shows the current and projected percentage distribution of persons aged 60 years and above in selected Asian countries for the period 2013 and 2050 [3]. Data show thatin 2013,Japan has the highest number of elderly (>30\%). By 2050 , it is projected that the proportion of elderly will comprise over 40 percent of the population in Hong Kong, Japan, and Korea, 30 percent and above in China, Singapore, Thailand, and Vietnam, and 20 percent and above in Brunei Darussalam, Cambodia, Indonesia and Malaysia.

Selected demographic characteristics illustrate the level of aging in these Asian countries (Table 1). The median age, or the age that divides the population in two halves of equal size, is an indicator of population aging [3].Median ages vary among the countries. In 2013, Hong Kong and Japanshowed 


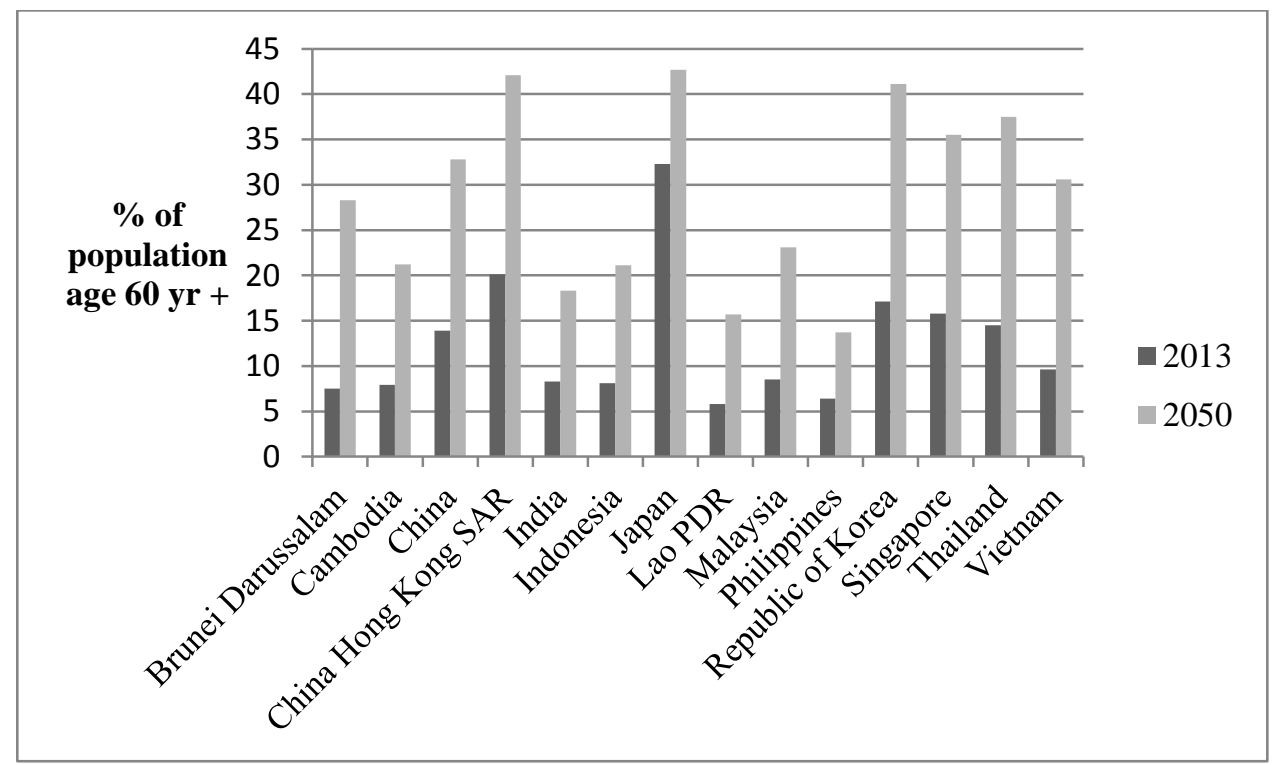

Fig. (1). Percentage of the population aged 60 years and above in selected Asian countries (2013-2050).

Source:Population Division of the Department of Economic and Social Affairs of the United Nations Secretariat (2013). World Population Prospects: The 2012 Revision. New York: United Nations.

Table 1. Median Age, Fertility Rates, and Life Expectancy at Birth in Selected Asian Countries

\begin{tabular}{|c|c|c|c|c|c|c|c|}
\hline \multirow{2}{*}{ Country } & \multicolumn{2}{|c|}{ Median Age (Years) } & \multicolumn{2}{|c|}{ Total Fertility Rate } & \multicolumn{3}{|c|}{ Life Expectancy at Birth (Years) } \\
\hline & 2013 & 2050 & $2005-2010$ & 2010-2015 & 2005-2010 & 2010-2015 & 2015-2020 \\
\hline Brunei Darussalam & 30.5 & 43.7 & 2.11 & 2.01 & 77.5 & 78.4 & 79.4 \\
\hline Cambodia & 24.4 & 36.2 & 3.08 & 2.88 & 69.5 & 71.6 & 73.5 \\
\hline China & 35.4 & 46.3 & 1.63 & 1.66 & 74.4 & 75.2 & 76.0 \\
\hline China Hong Kong SAR & 42.4 & 53.9 & 1.03 & 1.13 & 82.4 & 83.3 & 84.2 \\
\hline India & 26.4 & 36.7 & 2.66 & 2.50 & 64.9 & 66.3 & 67.5 \\
\hline Indonesia & 27.8 & 38.4 & 2.50 & 2.35 & 69.6 & 70.7 & 71.7 \\
\hline Japan & 45.9 & 53.4 & 1.34 & 1.41 & 82.7 & 83.5 & 84.3 \\
\hline Lao PDR & 21.4 & 34.3 & 3.52 & 3.05 & 65.8 & 68.1 & 70.2 \\
\hline Malaysia & 27.4 & 39.8 & 2.07 & 1.98 & 74.0 & 74.9 & 75.8 \\
\hline Philippines & 23.0 & 31.5 & 3.27 & 3.07 & 67.8 & 68.6 & 69.4 \\
\hline Republic of Korea & 39.4 & 53.5 & 1.23 & 1.32 & 80.0 & 81.4 & 82.6 \\
\hline Singapore & 38.1 & 50.0 & 1.26 & 1.28 & 81.2 & 82.2 & 83.1 \\
\hline Thailand & 36.9 & 51.1 & 1.49 & 1.41 & 73.3 & 74.3 & 75.2 \\
\hline Vietnam & 29.8 & 45.6 & 1.89 & 1.75 & 75.1 & 75.9 & 76.6 \\
\hline
\end{tabular}

Source: Population Division of the Department of Economic and Social Affairs of the United Nations Secretariat (2013). World Population Prospects: The 2012 Revision. New York: United Nations.

the highest median age at $>40$ years. Six countries (Cambodia, India, Indonesia, Lao PDR, Malaysia, Philippines) have younger median ages(i.e., below 30 years). The rest of the countries have median ages between 30-40 years.

By 2050, it is projected that the following countries will have the corresponding median ages (Table 1):
- 50 years old and above: China Hong Kong SAR, Japan, Republic of Korea, Singapore, Thailand

- 40 years old and above: Brunei Darussalam, China, Vietnam

- 30 years old and above: Cambodia, India, Indonesia, Lao PDR, Philippines. 
Population aging is largely a consequence of declining birth rates $[3,4]$. Low birth rates produce populations wherein the proportion of older persons increases while that of younger persons decreases.Countries where fertility remains high and has declined only moderately will experience the slowest rate of population aging.In general, fertility rates in the selected Asian countries have been declining since 1975. However, variations in fertility rates exist. Of the 14countries, five(Cambodia, India, Indonesia, Lao PDR, Philippines) have current fertility rates that are above the replacement level of 2.1. The rest of the countries have below-replacement fertility (Table 1).

Increased longevity also contributes to population aging [1]. Among the selected countries, Hong Kong, Japan, Korea, and Singapore currently have the highest life expectancies (80+ years), while India, Lao PDR, and Philippines have the lowest (60+ years). In all countries, life expectancy hasshown an increasing trend and is expected to increase further (Table 1).

As the population ages due to reduced fertility and increased longevity, countries in the region are faced with increased risks of chronic diseases. Data from WHO [5] show that, except for Cambodia,disability from chronic diseases in all the selected countries now exceeds that from communicable diseases (Table 2). For countries where high levels of chronic diseases and an increased elderly population accompany low levels of economic development,it is said that these countries have "grown older (and sick) before they have grown rich” [2].

\section{The Need for Evidence-Based Aging Policies in Asia}

Despite variationsin the rate of aging among Asian countries, it is clear that manycountries in the region, regardless of economic level,should start planning for the needs of elderly individuals aged 60 years and older, as these will comprise a significantly larger segment of their population in the near future [6]. Evidence-based policies which make use of scientific knowledge to inform the policy process and ensure that programs set in place meet the requirements of efficiency and effectiveness $[7,8]$ are needed. A report prepared by the US National Academy of Sciences in collaboration with the science academies in China, India, Indonesia, and Japan [6] stated that for many countries in Asia, the scientific basis for formulating evidence-based policy for aging is underdeveloped. The report stressed that many of the policy challenges associated with aging in the region can benefit from greater scientific knowledge, and that coordinated research activity among countries can compound the returns from investments in research made by individual countries.

\section{The Workshop on Healthy Aging in Asia}

In March 2013, the International Life Sciences Institute Southeast Asia (ILSI SEA) Region organized a conference on "Healthy Aging in Asia: Strategies to Meet Health and Lifestyle Challenges.”The conference was followed by a one-day workshop whose goal was to discuss aging issues in the region and identify ways to address these issues through scientific research. Workshop participants were experts in the field of aging from Asia and Australia. Participants were

Table 2. Disability-adjusted Life Years (DALYs) by Disease Conditions in Selected Asian Countries, 2004

\begin{tabular}{|c|c|c|}
\hline \multirow{2}{*}{ Country } & \multicolumn{2}{|c|}{ DALYs Lost Per 1000 Population } \\
\cline { 2 - 4 } & Communicable, Maternal, Perinatal and Nutritional Conditions & Non-Communicable Diseases \\
\hline Brunei Darussalam & 15.0 & 105.8 \\
\hline Cambodia & 182.1 & 160.2 \\
\hline China & 28.2 & 108.3 \\
\hline India & 105.3 & 138.2 \\
\hline Indonesia & 67.2 & 65.0 \\
\hline Japan & 5.6 & 145.6 \\
\hline Lao PDR & 126.8 & 119.0 \\
\hline Malaysia & 32.4 & 137.6 \\
\hline Philippines & 61.5 & 98.3 \\
\hline Republic of Korea & 8.9 & 82.2 \\
\hline Singapore & 11.4 & 116.2 \\
\hline Thailand & 60.7 & 108.2 \\
\hline Vietnam & 45.1 & \\
\hline
\end{tabular}

Source: Data calculated from Death and DALY estimates for 2004 by cause for WHO Member States. Geneva, World Health Organization. Retrieved from http://www.who.int/healthinfo/global_burden_disease/gbddeathdalycountryestimates2004.xls 
divided into two groups: the research discussion group and the policy discussion group. This report summarizes the outcomes of the two workshop groups.

The objectives of the discussion groups were:

1. To identify aging-related issues and formulate research priorities based on policy concerns regarding aging in Asia;

2. To put forward ideas for research topics and potential collaborations that will support effective aging policies;

3. To discuss ways to operationalize public-private partnerships that would facilitate the conduct of these researches.

\section{METHODS} sion:

The following questions were used to guide the discus-

- What are the important aging policy issues in the region?

- What has been done to address these issues?

- What types of evidence/research are needed to support aging policies in the region?

- What outcome measures/indicators/biomarkers and study designs are the most appropriate for the type of research needed? Do countries in the region have the resources/capabilities to carry out the above?

- Which issues/research will benefit most from regional cooperation and knowledge sharing?

- Can collaborative networks/public-private partnerships help; if so how can this be facilitated? What is the role of the private sector?

\section{RESULTS}

\section{Workshop Discussion: Policy}

The following policy issues were identified and are discussed below.

The challenge of translating research findings into policy initiatives.

A major challenge in Asia is convincing policy makers to use scientific knowledge as the basis for formulating policies. Translating research into policy actions is a long and difficult process in most countries. In Malaysia, sources which significantly influence policy are local advocacy groups at the grassroots level and feedback from other countries regarding which policies work best.

In Japan, findings from research do not seem to interest policy makers. While numerous studies focus on nutrition, food intake, and physical activity, the findings do not appear to influence policy to a significant extent.

One reason for this difficulty may be due to the fact that policy makers seek practical approaches to solving health problems. Thus, information needs to be presented in a way that can be translated and implemented rather than being theoretical and abstract. ly.

Inadequate financial support for health care of the elder-

\section{Inadequate Financial Support for Health Care of the Elderly}

Asian countries vary in terms of health care financing. Some countries such as Japan and Korea subsidize a relatively large part of health needs of their elders while others expect their citizens to take personal and family responsibility for health care. Singapore and Malaysia implement a policy of mandatory medical savings for healthcare needs in later life. In Malaysia, mandatory savings can provide for an individual's overall needs for an average of 3 years after retirement. The minimum retirement age in Malaysia is 60 years (as of July 1st, 2013), but as most Malaysians live up until age 77 or 78 , there is a big gap between what they can afford and what they actually need.

In Singapore, a major issue is limited public subsidy for long term care. To promote healthy aging, the elderly are encouraged and many actually participate in screening programs. However, many do not take follow up treatments because of the long-term financial costs. Fearing they might burden their children, many elderly people may choose to live with their chronic illnesses without receiving effective treatment.

For most countries in Asia, a policy of full government subsidy of payment for the health needs of the elderly is not a sustainable option. But at the same time, greater economic support is required for the elderly poor who have no means of paying for healthcare themselves.

Food insecurity among the elderly.

Familial connections in Asia differ from those in the west, and elderly people who live with their families generally do not face food security problems. However, some individuals may fall through the cracks, such as those whose children are estranged or have moved overseas, particularly in families fromlow socioeconomic levels.

\section{ETHNIC DIVERSITY OF ELDERLY POPULATIONS.}

Asian populations are comprised of diverse ethnic groups, which may account for differences in risk for chronic disease. In countries like Japan, the aging population is relatively homogeneous, but in countries such as Singapore, the population is heterogeneous. A policy may be appropriate for one group but not for another. These population differences should be considered when developing preventive strategies.

Ways to address aging issues in Asia were suggested and are discussed below.

Prevention of disability through a pre-emptive and integrated policy approach to diet, physical activity and aging.

Effective healthy aging policies call for pre-emptive and targeted interventions to be taken. The aging population are a heterogeneous group, with varying needs depending on age, levels of illness or disability and financial or family support. 
Policy planning should take into account distinct population segments of older individuals.

One segment is the population that has reached their midlife years (i.e., 40+ years). These individuals are economically productive, have adequate spending power with good incomes. They aim to remain productive for at least another twenty years and are likely to institute necessary lifestyle changes. This middle-aged group represent a target of policies that aim to prevent disease and disability by promoting healthy lifestyles.

A second group comprises those individuals aged 60-69 years, or 'young elderly'. Some of them may be healthy and active, with income from savings in their employment years. Others may have chronic medical conditions and are in need of active management of their conditions. Policies should target this group for effective long-term treatment .

The third group comprisesthose individuals aged 70+ years, or 'old elderly' the majority of whom will have established health problems. Increasing cost of care is a salient issue,coupled with the need to provide more communitybased interventionsand accessible services in terms of screening, medications, and long-term care.

Segregating the aging population into these three groups allows the formulation of policy interventions that address each group's distinct health needs. Messages and other interventions may thus be tailored to the different lifestyles and goals that characterize each group. As an example, in the $40+$ age group, the message can be "live healthy lifestyles and participate in disease screening in order to stay healthy and productive." In the 60+ group, the message can vary depending on level of health and mobility, focusing on either preventing or managing existing illness. In the last group (70+ years), the message may focus on maintaining quality of life and appropriate treatment of existing age-related ailments.

An integrated approach to prevent disability should involve the government, food and fitness industries, and academics. The objective is to change the attitudes and behaviour of the elderly, their families, and health care providers, both actively through communication and education and passively through the built environment. Actions to achieve these objectives include the following:

\section{Identify best practices.}

A pragmatic approach should be taken wherein best practices from countries around Asia that already have programs in place are identified and adopted.

\section{Identify Cost-Effective Policies with Proven Ability to Improve Health.}

There is a need to look further into the evidence base to identify cost-effective policies from other countries that are proven to improve health. Measureable statistics that clearly demonstrate effectiveness in improving health while reducing costs will provide the concrete evidence needed by policy makers.
Develop Improved Communications to Increase Understanding and Promote Behaviour Change

Messages that are developed andtested within a specific cultural contextwill result in improved understanding and behavioural change among the elderly. Deleterious beliefs may limit the use of certain foods despite scientifically proven health benefits. Knowledge of existing attitudes, beliefs and practices regarding diet and physical activity will help identify barriers that need to be overcome. These considerations may be incorporated into messages that aim to achieve change.

\section{Use Families and Health Care Practitioners as Targets for Communication}

The family acts as the gatekeeper of nutrition information for the elderly and determines their access to health care and physical activity. Policies should encourage the education and involvement of family members in caring for their elders.

Both general practitioners and practitioners of traditional medicine hold attitudes and beliefs which may not be consistent with recommended nutrition practices. The need to educate and change the attitudes of these health professionals regarding nutrition and physical activity should be considered.

Determinepeople'sawareness and knowledge about healthy aging.

The level of public awareness about healthy aging, particularly among those in the mid-life stage $(40+$ years old), may determine acceptance of policies geared towards healthy aging. Thus, there is a need to identify gaps in individuals'awareness and their readiness to change, which may affect participationin and use of aging policies and programs.

Delivery of integrated services for disabled and elderly people.

Countries should provide standards and harmonized guidelines for integrated service to promote aging in place. Aging in place policies encourage the elderly to live out their lives in their community, staying as functional, independent and mobile as much as possible. Even if they lose their functional ability, the elderly are supported by their family and community rather than being institutionalized. Aging in place is consonant with the Asian emphasis on the children's duty to support, honour and care for their parents in their old age.

External services that enable older individuals to age gracefully in place provide community-based interventions that support the elderly and their families. The effective delivery of these services may be helped by the following:

- Harmonize existing services across agencies to avoid overlap.

- Improve the efficient use of manpower resources by integrating similar functions into a single agency or department, and by providing training and capability building programs. 
- Draft guidelines for delivery of services for aging in place.

- Develop schemes to encourage the uptake and use of programs and services for the elderly.

- Involve all stakeholders and agencies (government, nongovernment organizations, volunteer groups) in the implementation. Tapping on the experiences of individuals and organizations to identify best practices, by finding out what works or does not work, saves time and money.

- Seek the help of researchers in the region to identify what types of research can drive these initiatives and ways to measure their success.

- Organize a dialogue or forum to share best practices.

How Asian countries address problems associated with aging are illustrated in several country examples below.

In Singapore, groups are working towards closing the gap for needy elderly. For the elderly who live alone, a centralized Meals on Wheelsis run by an organization called Centre for Enabled Living (CEL). CEL coordinates with church groups and philanthropic organizations to prepare foods which are delivered to needy families during mealtimes throughout the day. Nutritional guidelines for service providers are developed to ensure foods that are served are safe and palatable, particularly for households with no refrigerators. CEL is a government initiative whose goal is to promote healthy aging and better quality of life. Another organization is the Agency of Integrated Care which provides intermediate and long term care for the elderly in nursing homes, as well as food and financial assistance to families in need.

Other initiatives in Singapore are:

- The Health Ambassador Network is an organization of well elderly who have been trained in health and physical activity. The health ambassadors target elderly individuals who consult doctors but fail to follow through on medical advice. These elderly individuals need someone they can trust to get around barriers and superstitions that prevent them from taking action on their conditions. The trained ambassadors speak to their peers and mobilize them into accessing facilities such as those for physical activity.

- The built environment in Singapore is being re-designed to be elderly-friendly. Exercise equipment in parks aremodified to make them safe for use by seniors.

- The Singapore Health Promotion Board is building up capacity in motivational interviewing for health workers to enable patients to overcome barriers to behaviour change. Health service providers are trained to explore fundamental constraints faced by individuals in changing their behaviour and to address their ambivalence to change.

India was among the first countries to ratify the UN Convention on the Rights of Persons with Disabilities (UNCRPD) and emphasizes that the health services needed by persons with disabilities should be provided as close as possible to people's own communities, including in rural
areas.Issues related to population aging are very well addressed in India by the National Rural Health Mission and the National Programme for the Health Care of the Elderly (NPHCE). One of the visions of NPHCE is to promote the concept of Active and Healthy Ageing.However, the outreach of these programs country wide is minimal and it needs to be elaborated to all urban and rural parts of the country.To examine the health, economic and social wellbeing of India's elderly population, the Longitudinal Aging Study in India (LASI) is following a nationally representative sample of roughly 30,000 Indians ages 45 and older over time. LASI is modelled after the Health and Retirement Study (HRS) in the United States and is comparable to similar studies in Asia, including the Chinese Health and Retirement Longitudinal Study (CHARLS), the Japanese Study of Aging and Retirement (JSTAR), and the Korean Longitudinal Study of Aging (KLoSA).

In Vietnam, there is a national aging network which is an integrated organization of community-based aging clubs. The aging clubs prevent social isolation not only among elderly who live alone but also among elderly living with their families who are lacking in peer contacts due to the demands of looking after their grandchildren.

In Japan, health practitioners organized aging clubs to bring together elderly people after the tsunami. Group physical activities organized by these clubs prevented social isolation among the elderly.

The following are potentially good practices, although not necessarily based on actual country experiences.

- Health practitioners should provide lifestyle prescriptions so that they are not just treating chronic conditions with drugs but also with physical activity and nutrition recommendations. Lifestyle prescriptions are usually recommended after an individual is diagnosed with a chronic disease condition. However, it would be optimal for lifestyle measures to be prescribed before the individual even falls ill - called lifestyle 'preprescription'.

- There can be a distinct group of mid-level health practitioners who go into the community and follow up on elderly who fail to follow through on medical advice. This group of professionals would be alike social workers, except that they follow up on medical care, physical activity, nutrition and lifestyle prescriptions. They may also accompany seniors during leisure physical activities such as walking in the park and shopping.

- There can be a whole family approach involving older children and grandchildren who support nutrition and physical activity of the elderly.

- Younger children and other family members may be providededucation and training. Such family education may alsofacilitate early intervention for younger members with similar health problems.

- Mid-level practitioners or family counsellors can be mobilized to follow up on lifestyle prescriptions not only for the elderly but for the whole family.

- Workplace health programs should consider the needs of the 'well' elderly. 
- The built environment can be designed to promote healthy aging by providing easily accessible parks in urban areas and encouraging their use through family counsellors.

\section{WORKSHOP DISCUSSION: RESEARCH}

Participants agreed that it is not the issue of longevity that needs to be addressed, but rather, healthy aging. Research should therefore be directed towards achieving better health and quality of life in the Asian context and environment rather than identifying factors that lead to longer life.Health expectancy (i.e., the number of years in full health that a person can expect to live), rather than life expectancy (the average number of years a person can expect to live), is the more relevant issue. Notably, the concept of health expectancy does not yet exist in many countries in the region.

There is a need to examine the disability process particularly in developing countries. In the transition from no disease to disease, disease to disability, and disability to death, participants asked thequestion - Which transition should be the focus? Alife course approach should be taken in examining aging-related disability. The healthpathway is a two-way process that goes from a healthy state to a diseased state, and back. There is a need to understand the onset and course of the aging disability process, and to identify the factors and pathways leading to and away from disability among Asians, using available longitudinal data. Standards of physical fitness for Asian populations are also needed in order to identify the start and end points of the aging disability process.

A crucial factor in healthy aging is the maintenance of independence and autonomy as a person grows older. There is a need to look into the role of technology in allowing the elderly to achieve independence and mobility in the face of increasing disabilitiesand in a developing country context. This is particularly important for Asia where there are many developing countries and where, due to its larger population size, total numbers of elderly exceed those in Europe and America.

\section{Proposed Research that May Benefit from Regional Cooperation}

Multi-disciplinaryand policy-relevant research is needed to cover the physical, social, emotional, and political aspects of aging. Approaches include basic biological research, psychosocial behavioural research, translational research, policy driven research including program evaluation, and research about choice and decision. Results from research should be actionable and capable of being translated into policy. Topics that should be better studied in Asian populations are discussed below.

Identify effective policies that promote healthy aging - the role of "success stories." One way to examine the bigger picture of healthy aging is to find out what works by looking back through history. For successive stages in the life of an aging individual (i.e., from no disease to disease, disability, and death), there are known risk factors that contribute to the decline in health, such as smoking, diet, lifestyle, environment, etc. Successful strategies that prevent the adverse tran- sition can be identified from studies of policies and programs that have been implemented in different countries. These "success stories" include interventions and technology that promote independence and autonomy in later life and can be obtained from published literature. The research group can identify success stories that are relevant for Asia and provide these to policy makers. Future research should more clearly include the physical and psychosocial aspects of aging, as well as the built environment (environmental engineering and building design).

Identify mid-life strategies that promote healthy aging.

Factors that cause the transition into disability in aging need to be understood. What takes an individual to disability is probably those diseases that have long incubation times and the most likely period when this occurs is in midlife. Thus policy research for the future should be looking at evidence for appropriate strategies at midlife that ensure good aging in the elderly. Strategies for cardiovascular disease are a good example of successful programs, strategies for cancer and diseases of the nervous system are being developed. A possible age range to target is from $50-55$ years because in most countries, individuals are considered aging from 55 years onward.

Examine dietary factors in healthy aging.

The following diet-related factors need greater in-depth research:

Indigenous functional foods and ingredients that benefit the elderly.

In Singapore, there is a need to examine what comprises a healthy diet for older populations. A healthy diet is one that, in addition to supplying needed nutrients, includes functional foods and ingredients for elderly people which can be promoted among Singapore's food hawkers.

\section{Advanced glycated end products (AGEs) in Asian diets}

In India, diabetes develops at an early age at least 5 to 10 years ahead of counterparts worldwide. One newly emerged dietary factor that contributes to diabetes development is advanced glycation end products (AGEs). AGEs are glycotoxins resulting from a chemical reaction between sugars and protein, from endogenous reactions, and from cooking and thermal processing of foods.AGEs are highly oxidant compounds with pathogenic significance in diabetes and other chronic diseases.Since the Asian diet differs from the western diet, there is an imperative need for studies on the health consequences of dietary AGEs, including the development of an AGE food composition database. Knowledge regarding levels of AGEs intake in different countries based on local diets and native culinary techniques may contribute to the development of nutrition policies that will help reduce diabetes prevalence in the region. diets

Effects of modernization and culture change on Asian

The effects of cultural change on Asian diets and how this impacts the aging process should be examined. The causes and factors (e.g., lifestyle behaviour andsocial environment) that give rise to specific dietary patternsand lead to disease acceleration should be identified. 
Vitamin D deficiency and aging in Asian populations.

It is important to look into vitamin D deficiency in tropical countries with abundant sunlight. Among the elderly, studies show that vitamin D deficiency is associated with chronic diseases including type 2 diabetes.

Cognitive function and diet in aging.

Cognitive function as a contributor to physical function in aging and its relationship with diet needs to be studied. Loss of cognitive function has a devastating impact on functional independence. The increased incidence of cognitive impairment and Alzheimer's disease in aging populations is a growing problem in need of an effective solution. Whilst studies in the west suggest a protective effect of the Mediterranean diet, the Asian dietary pattern that may be protective should be firmly identified.

The Asian gut microbiome.

Dietary patterns in Asia are quite different from those in the west. The type of diet influences the type of gut microbiota which in turn determines the function of our genome, with corresponding effects on aging.Probiotics developed in a laboratory in India which have been shown to improve glucose tolerance among infants, may have implications for later health and aging.

DevelopAsian standards for sarcopenia and BMI.

Sarcopenia is muscle atrophy during aging and is characterized by decreasing muscle mass and function. In 2010, the European working group established standardsfor measuringsarcopenia while the United States and Europe established the international definition in 2011. The Asian population has no standards for sarcopenia and Asians are very different compared with Caucasians, so it is important to establish a sarcopenia definition that is appropriate.

Regional data for sarcopenia, body composition, BMI, and physical activity can be improved by pooling together all available data from studies done in Asian countries like China, Korea, Japan and India. By pooling together and standardizing the measures, regional cut-offs may be derived.

The condition of 'metabolic obesity' among lean Asian people should be an important research priority.South Asians develop alterations in metabolic risk factors such as glucose, insulin, lipid levels and inflammatory cytokines at significantly lower body mass indices than Caucasians and more research is needed in this direction.

DevelopAsian standards for disability.

According to aJapanese participant, attempts at promoting the development of a standardized disability index for Asian populations hasso far not been successful. In the European Union (EU), a standardized disability measure has been developed for 25 countries - the General Activity Limitation Index (GALI). The use of this measure across countries enables comparability of results. Another EU group the Budapest initiative - is now developing a wider concept of health. It is important that Asian countries should work together to develop similar measures.

Examine inflammation and other biomarkers in aging.
Clinical conditions such as Alzheimer's disease, obesity, diabetes, and other chronic diseases are related to aging. A common underlying cause for these conditions is inflammation, although there are various underlying mechanisms for inflammation. Subclinical inflammation is present even in healthy old people. Since inflammation covers a broad spectrum of conditions and diseases in the elderly, its broad use as an indicator should be a focus of research.

There is a need to identify a panel of biomarkers of aging, which includes inflammation, and to validate these biomarkers. There is currently alack of biomarkers at the genomic, proteomic, or metabolomic level. Predictive biomarkers of aging have tobe put together in a way that would inform policy makers how rapidly the population is aging even before reaching old age, or that will reflect the effects of interventions and policy actions in preventing disease and disability. Biomarkers, yet to be identified or developed,that predict compression of morbidity in aging are essential to inform policy and preventative strategy.Research on the Asian "clinical omics" studies should be expanded in various parts of Asia.

Examine the interaction between biological and psychosocial aspects of aging.

There isa need to examine how psychosocial health indicators interact with the biological markers of aging- for example, depression and cardiovascular disease.There is emerging evidence of a relationship between telomere shortening and psychological stress. Caregivers of the elderly are also important. In studies of carers of elderly patients,it was shown that carers of Alzheimer's patients have a five-fold risk of developing the disease. Other examples are adverse experiences in childhoodthat cause DNA damage, andgenes associated with resilience as a psychological phenotype.

Establish a standard definition of healthy aging in Asia.

There is presently no consensus on theconceptual and operational definitions of healthy aging. Biologists, psychologists, and sociologists define healthy aging in different ways. A multi-dimensional definition with corresponding measures is useful for policy makers, as well as a global measure that can be acted upon and used for program evaluation.

To define biological aging, it is important to identify what biomarkers define the onset of aging andindicate healthy aging, and to define the role of independence and autonomy in extending life span.There is a need to differentiate the functional markers of aging from those of disease, as well as to identify markers of biological (as opposed to chronological) aging and how they relate to average lifetime in different populations.

\section{Examine the intergenerational aspect of aging.}

Inadequate nutrition during foetal lifeevidently affectthe aging process in later life. This has been demonstrated in Dutch studies which examined the effects of famine during pregnancy on offspring adult health. Mid-life measurements of biomarkers are important because legacy effects or metabolic memory effects later determine offspring phenotypes.During pregnancy, trimester-based measurements of biomarkers can be done to determine the risk for gestational 
diabetes in women because 'transient gestational diabetes' if neglected, would result in future diabetes not only in mothers but also increases the risk for diabetes in the offspring.

Compile data on health expectancy in the region.

Data on health expectancy in southeast Asian countriesare needed. A standard definition of health expectancy must be established to allow comparison across countries. The level of health expectancy is an indicator of performance in terms of a country's health policies. Countries can be ranked according to health expectancy. Such ranking may motivate policy makers and researchers to examine reasons underlying a certain level of performance. This will, in turn,provide strong justification for research funding support.

Develop future diagnostics to measure aging.

The future heralds new diagnostics that can accurately predict whether a person is aging too fast or if his genetic background makes him age too fast, in order to find ways to alleviate the insults that cause DNA damage and accelerate aging. Since it is known that damage to the genome affects all systems, these diagnostics should be useful from conception onwards. An example is diabetes. Thirty years ago, type 2 diabetes occurred only in older populations. But now, type 2 diabetes (particularly in Asians) occurs earlier and at a very productive age. Thus aging plays an important role in onset of the disease and the treatment modality should be modified from that of 30 years ago.

Develop culturally appropriate instruments.

Instruments appropriate for use in the Asian cultural context need to be developed. An example is the quality of life measurements. There are currently no available Asianderived quality of life measures. Instruments that come from western countries have to be revised and modified to make them useful in Asia.

\section{FINDING RESOURCES AND WAYS TO CARRY OUT THE SUGGESTED RESEARCH}

In Order to Raise Needed Resources to Carry Out the Proposed Researches, Particularly for Poorer Countries in Asia, the Following Suggestions were Made:

Establish networks and linkages.

The current trend in doing aging research is one where multiple institutions and countries work together to examine complex problems. Aging is a complex area that requires a multidisciplinary and regional approach. These complicated approaches require large amounts of input which a single individual or institution isunable to provide.Thus the first step is to establish linkages and ILSI SEA is an important catalyst to create these regional linkages.

Conduct a regional workshop or conference on "success stories" in Asia.

A regional workshop or conference can be held, wherein participants present successful programs and policies that are transportable. Information obtained from success stories help to define issues and gaps that need further study and are appropriate for funding.
Research grants support.

An important resource is grant funding support. Chances of success fora grant applicationare increased by including a developing country partner. This works best for countries like Philippines and Indonesia where research resources are very scarce. ILSI SEA may use its organizational status to apply for research funds that are awarded to institutions rather than individuals. Asian countries should tap on research collaborative partnerships by targeting funding agencies such as the Welcome Trust, Human Frontier Science Programme, European Union F7, National Institutes of Health, and other avenues. Similarly, research on aging could be elaborated and extended by the appropriate project applications in response to bilateral international research calls.

Exploit opportunities for public-private partnerships.

Opportunities to attract industry in providing resources to academe for research should be actively sought. Companies are increasingly doing less research and instead are looking to universities and research institutes to conduct research in their realms. A recent meeting event brought researchers from four countries in the region to share information on their ongoing studies, methodology and best practices, with positive feedback. More such events could be organized by a consortium. ILSI SEA can facilitate the creation of such a consortium.

Establish a regional consortium.

The establishment of a regional consortium canprovide fund resources, facilitate meetings and provide working groups which bring together individuals from various disciplines to align research priorities and methodologies.Suggested names for a consortium are:

- Consortium for Ageing Research and Education in Asia (CARE-ASIA)

- Asia Pacific Ageing Consortium (APAC).

The consortium will make it possible for researchers to develop consensus on defining health indicators for the region and define the Asian concept of healthy aging, from which a collaborative research project(s)using a multidisciplinary approach can be undertaken. Research project areas that are of common interest across countries in the region can be identified in workshops on key research questions, with the goal of developing the skeleton of the project activities, agreeingon its focus, identifying areas that affect policy and can translate into practice, and planning for future activities.

\section{SUMMARY OF CONSOLIDATED WORKSHOP DIS- CUSSIONS}

There are huge gaps in data and knowledge on aging in Asian countries, limiting the formulation of evidence-based aging policies in the region. The following points were made at the end of the discussions:

- Analysis of existing evidence is needed in order to identify the gaps that need to be filled. The important question is "what are the steps that can be taken to bridge the lack of research on Aging in Asia, and Southeast Asia in particular?" There is a need to determine how current 
findings from other parts of the world can be translated with sufficient confidence to make policy recommendations for this region.

- Both the policy and research discussion groups suggested the formation of a regional multidisciplinary consortium or task force to guide future actions. The goal is to improve scientific knowledge on aging which will support the formulation of evidence-based policies. The initial steps to be taken by the task force/consortium are to create a vision statement, identify areas of collaboration through research, and create terms of reference. The recommendations put forward in the workshop discussions may serve as a guide for formulating the research agenda that will support aging policiesfor the region.

\section{CONFLICT OF INTEREST}

The authors confirm that this article content has no conflicts of interest.

\section{ACKNOWLEDGEMENTS}

We thank the following workshop participants for contributing to the richness of the discussions: Ms. Samantha Bennett (formerly with Singapore Health Promotion Board), Dr. Judith Borja (University of San Carlos, Philippines), Dr. Conor Delahunty (CSIRO Australia), Ms. Yashna Harjani (Pepsico Thailand), Dr. Vivienne Hunt (Abbott Singapore), Dr. Kom Kamonpatana (Unilever), Dr. AnisLarbi (Singapore Immunology Network), Mr. Benjamin Lee (Singapore Health Promotion Board), Dr.Lim Min Chin (Republic Polytechnic, Singapore), Dr. Yen Ling Low (Abbott Singapore), Dr. Ho Thu Mai (National Institute of Nutrition, Vietnam), Dr. Kenjiro Ono (Kanazawa University, Japan), Dr. Eric Ravussin (Pennington Biomedical Research Center, USA), Ms. Gae Marie Redoblado (Unilever),Dr. Yasuhiko Saito (Nihon University, Japan), Dr. Chong Meng Tay (National University Hospital, Singapore),Ms. Mia Eng Tay (Nanyang Polytechnic, Singapore), Ms.Hui Kheng Toh (Singapore Polytechnic), Dr. Shinya Toyokuni (Nagoya University, Japan), Dr.Ardyvan Helvoort (Danone Research, Singapore), Mr. Paul Vardon (Australia), Dr. Chi-Pang Wen (National Health Research Institutes, Taiwan), Dr. Yosuke Yamada (Kyoto Prefectural University of Medicine, Japan), Dr. Ryuji Yamaguchi (ILSI Japan), Mr. Geoffrey Smith (ILSI SEA), Ms. Justine Gayer (ILSI SEA), Mr. Keng Ngee Teoh (ILSI SEA), Mrs. Boon Yee Yeong (ILSI SEA). Also acknowledged are theco-organizers Singapore Health Promotion Boardand Commonwealth Scientific and Industrial Research Organization (CSIRO) Australia.

Sources of funding for the workshop and for manuscript preparation: ILSI SEA Region, CSIRO Australia, Singapore Health Promotion Board

\section{SUBMISSION DECLARATION}

The submitted work has not been published previously, is not under consideration for publication elsewhere, and its publication is approved by all authors. If accepted, it will not be published elsewhere including electronically in the same form, in English or in any other language, without the written consent of the copyright-holder.

\section{ROLE OF THE FUNDING SOURCE}

International Life Sciences Institute Southeast Asia (ILSI SEA) Region, Singapore Health Promotion Board, and Commonwealth Scientific and Industrial Research Organization (CSIRO) Australia provided financial support for the conduct of the workshop. ILSI SEA and the Workshop Committee were involved in the writing of the report and in the decision to submit the article for publication.

\section{REFERENCES}

[1] United Nations Population Division. Statistical yearbook for Asia and the Pacific 2012. New York: United Nations [cited 1 July 2013]. Available from http://www.uis.unesco.org/Library/Documents/statistical-yearbook-asia-pacific-country-profileseducation-2012-en.pdf

[2] UN office for the coordination of humanitarian affairs. Asia: isolation, poverty loom for an aging population.IRIN Humanitarian news and analysis [newspaper online].2012 February 14 [cited 1 July 2013].Available from http://www.irinnews.org/report/94856/

[3] United nations department of economic and social affairs/population division. World population prospects: The 2012 revision, key findings and advance tables [homepage on the Internet].c2013 [cited 1 July 2013] . New York: United Nations. Available

http://esa.un.org/unpd/wpp/Documentation/publications.htm

[4] United nations population division. Statistical yearbook for Asia and the Pacific 2011. New York: United Nations. Available from: http://www.unescap.org/stat/data/syb2011/I-

People/Population.asphttp://www.unescap.org/stat/data/syb2011/IPeople/Population.asp

[5] World Health Organization. Death and DALY estimates for 2004 by cause for WHO Member. Geneva, Switzerland. Available from: http://www.who.int/healthinfo/global_burden_disease/gbddeathdal ycountryestimates2004.xls

[6] Chinese Academy of Social Sciences, Indian National Science Academy, Indonesia Academy of Sciences, National Research Council of the U.S. National Academies, Science Council of Japan. Preparing for the challenges of population aging in Asia: Strengthening the scientific basis of policy development. Washington (D.C.): National Academies Press 2011[cited 1 July 2013]. Available from: http://www.nap.edu/catalog.php?record_id=12977

[7] Head BW. Three lenses of evidence-based policy. Aust J Publ Admin 2008; 67: 1-11.

[8] Brownson RC, Chriqui JF, Stamatakis KA. Understanding evidence-based public health policy. Am J Public Health 2009; 99: 1576-83.

Received: September 05, $2013 \quad$ Revised: December 02, 2013

Accepted: December 02, 2013

(C) Pin et al.; Licensee Bentham Open.

This is an open access article licensed under the terms of the Creative Commons Attribution Non-Commercial License (http://creativecommons.org/licenses/by-nc/3.0/) which permits unrestricted, non-commercial use, distribution and reproduction in any medium, provided the work is properly cited. 